\title{
Anger in Elderly Patients with Depressive Disorders
}

\author{
Sengmi Baeg${ }^{1}$, Seong Keun Wang', Ik Seung Chee', Soo Yeong Kim² and Jeong Lan Kim ${ }^{1}$ \\ ${ }^{1}$ Department of Psychiatry, School of Medicine, Chungnam National University, Daejeon, Korea \\ ${ }^{2}$ Department of Preventive Medicine \& Public Health, Eulji University School of Medicine, Daejeon, Korea
}

\begin{abstract}
Objective This study was conducted to investigate anger in elderly patients with depressive disorders.
Methods The subjects included 216 elderly patients with depression and 198 controls. All subjects were assessed by the State and Trait Anger Inventory (STAXI), Aggression Questionnaire (AQ), Reaction Inventory (RI).

Results Elderly patients with depressive disorder showed lower levels of trait anger and anger expression on the STAXI, lower levels of verbal aggression and hostility on the $\mathrm{AQ}$, and lower levels of anger reaction to the unpredictable disruption and disturbances factor, the embarrassing circumstances factor, and the personal disrespect factor on the RI than the controls. In the depression group, the severity of their depression was positively correlated with the trait anger, state anger, anger expression (except 'anger control') scores on the STAXI; the physical aggression, anger, and hostility scores on the AQ; and the anger reaction to unpredictable disruption and disturbances factor, the embarrassing circumstances factor, and the personal disrespect factor scores on the RI. However, the severity of depression negatively correlated with only anger control on the STAXI. In the linear logistic regression analysis, as there were higher levels of state anger seen in the STAXI, anger on the AQ, anger reaction to unpleasant factors on the RI, and therefore the likelihood of depression would be higher.

Conclusion Elderly depressive patients are less likely to have anger traits and to express anger than normal elderly. However, in elderly depressive patients, the higher they have severity of depressive symptoms, the higher they reported anger experience and anger expression.
\end{abstract}

Psychiatry Investig 2011;8:186-193

Key Words Depression, Anger, Aggression, Aged.

\section{INTRODUCTION}

Little attention has been focused on negative emotion, such as anger in the elderly. Anger refers to an emotional state varying from mild annoyance to rage. ${ }^{1}$ Anger is sometimes mingled with other terms having similar meanings such as aggression and hostility. ${ }^{2}$ Aggression refers to the delivery of any form of definite and observed harm-giving behavior towards a target, and is divided into physical-verbal dimensions, active-passive dimensions, and direct-indirect dimensions. ${ }^{3}$ While aggression embraces anger (affective aspect), hostility (cognitive aspect), and aggressive behaviors (behavioral aspect) in its broad meaning, the term can also be defined as limited to clear aggressive behaviors. ${ }^{3}$ Hostility is a cognitive aspect of aggression

Received: November 26, 2010 Revised: March 12, 2011

Accepted: April 12, 2011 Available online: August 11, 2011

$\triangle$ Correspondence: Jeong Lan Kim, MD, PhD

Department of Psychiatry, School of Medicine, Chungnam National University, 33 Munwha-ro, Jung-gu, Daejeon 301-721, Korea

Tel: +82-42-280-7287, Fax: +82-42-280-7886, E-mail: kimjl@cnu.ac.kr

(a) This is an Open Access article distributed under the terms of the Creative Commons Attribution Non-Commercial License (http://creativecommons.org/licenses/bync/3.0) which permits unrestricted non-commercial use, distribution, and reproduction in any medium, provided the original work is properly cited. and is defined as overarching negative beliefs about other such as cynicism and mistrust. ${ }^{4}$

In a study of changes in hostility over a lifetime, it has been reported that hostility scores were higher when ages were lower and decreased in the middle years of the lifetime while increasing slightly during senescence. ${ }^{5}$ Another study has been reported that as people age, their tendency to have hostility toward others increased, while their tendency to express anger and aggression decreased. ${ }^{4}$

Schless et al. reported that the degree of hostility turned inward was correlated with the severity of depressive episodes in a study of the relationship between anger and depression. ${ }^{6}$ Other studies suggested that depressed individuals have significantly higher rates of aggression than the nondepressed controls, and that anger and aggression tend to decrease once the depressive episode subsides. ${ }^{7-12}$

In summary, hostility toward others tends to increase while the expression of anger and aggression tends to decrease as individuals age. Anger and aggression due to depression tend to increase with age. Thus far, anger and aggression have been dealt with and studied in relation to diverse psychiatric disorders such as dementia, ${ }^{13-15}$ somatization disorder, ${ }^{16,17}$ depres- 
sion, ${ }^{12}$ suicide, ${ }^{18}$ and Hwabyung ${ }^{19,20}$ or other social problems. However, previous studies have concentrated on one-dimensional qualitative or quantitative assessments of anger in relation to depression, and to these authors' knowledge, no study has focused on anger in terms of late life depression.

This study is intended to examine the degrees of anger in elderly patients with depressive disorders and to investigate the correlations between anger and depression symptoms and risk factors for depression in regards to diverse anger factors.

\section{METHODS}

\section{Subjects}

\section{Depression group}

The subjects were patients who met the criteria for depressive disorders, such as major depressive disorder, dysthymic disorder, and depressive disorders that were not otherwise specified, with Diagnosis and Statistical Manual of Mental Disorders-Fourth Edition (DSM-IV). They were assessed through structured interviews using Mini International Neuropsychiatric Interview (MINI), ${ }^{21}$ history taking, and medical record reviews by psychiatrists. They were 60 year-old or older who reported depressive symptoms in psychiatric outpatient clinics Chungnam National University Hospital from June, 2009, through February, 2010.

Subjects were excluded that had been diagnosed with depressive episodes of bipolar disorder or depressive disorder with psychotic symptoms, patients had any neurological diseases such as Parkinson's disease, cerebrovascular disease, brain tumor, and normal pressure hydrocephalus in history or neurological examinations, patients with depression accompanying cognitive disorders including dementia, and patients with any history of alcohol or other substance use disorder. A total of 216 patients ( 46 men, 170 women, mean age $71.6 \pm 6.3$ years) participated.

\section{Normal elderly}

From July, 2009 through August, 2009, psychiatrists conducted structured interviews using the MINI and history taking on 215 persons who volunteered to participate in the study. The subjects were taken from among 60-year-old or older persons residing in the community.

Seventeen elderly were excluded who had any psychiatric disorder based on DSM-IV diagnostic criteria, any neurological disorder, systemic disease or who were taking drugs that could affect psychiatric symptom(s) or cognitive functions and did not complete questionnaires. Of the 215 persons, a total of 198 (70 men, 128 women, mean age $72.6 \pm 5.9$ years) participated.

\section{Procedure}

All subjects provided written informed consents before study entry. Subjects were selected from those who agreed to participate in the study through structured interviews by using MINI, history taking, and medical record reviews conducted by psychiatrists. Thereafter, the subjects' depression, anger, and aggression were assessed using various scales.

This study was approved by the Institutional Review Board (IRB) of Chungnam National University Hospital (Approval No.: 0907-64).

\section{Diagnostic assessment}

\section{MINI}

This is a short structured diagnostic interview, developed by Sheehan ${ }^{21}$ for DSM-IV and ICD-10. MINI can be used by psychiatrists or clinicians with minimal training. The interview time is around 15 minutes.

\section{Depression rating}

\section{Hamilton Depression Rating Scale (HDRS)}

It is designed to rate the severity of depression and the efficacy of treatment by observation and interview, ${ }^{22}$ and is a revision of the 17 items most widely used in clinics or studies standardized by Yi et al. for Koreans. ${ }^{23}$ For each depressive symptom, nine items are scored as $0-4$ points, and eight items are scored as $0-2$; the range of total scores is $0-52$ points. A higher score means more severe depression.

\section{Beck Depression Inventory (BDI)}

It is composed of 21 items self-report questionnaire, and is developed to assess the existence of depressive symptoms and the severity of those symptoms. ${ }^{24}$ The range of responses to each depression symptom is $0-3$ points, and a higher score means more severe depression. The Korean version of the BDI was standardized by Han et al. ${ }^{25}$

\section{Geriatric Depression Scale (GDS)}

This is a self-report depression scale, composing of a 30 item list for elderly persons. ${ }^{26,27}$ It can be responded to using yes or no answers; the range of scores is $0-30$ points.

\section{Anger assessment}

\section{State and Trait Anger Inventory (STAXI)}

This self-report anger scale was developed by Spielberger et al. $^{28}$ in order to measure anger experience factors and anger expression factors. It was standardized for Koreans by Chon et al. ${ }^{29}$ This scale has a total of 44 items, consisting of 10 items 
for state anger, 10 items for trait anger, and 24 items for anger expression. The trait anger items are composed of items for trait anger temperaments and those for trait anger reactions and the anger expression items are divided into three, Anger in, Anger out, and Anger control.

Aggression Questionnaire (AQ)

This has 29 items, self-rated, and 5-point Likert scale developed by Buss et al. ${ }^{30}$ in order to assess aggression, anger, and hostility and was standardized for Koreans by Seo et al. ${ }^{31}$ Seo et al. suggested four factors, including physical aggression, verbal aggression, anger, and hostility, this study was adopted those 4 factors to explore characteristics of anger and aggression on elderly.

Reaction Inventory (RI)

Cho et al. ${ }^{32}$ standardized Korean version of RI Evans et al. ${ }^{33}$ It is composed of 76 items, which are specific stimulating situations that may incite anger. Cho et al. discovered four related factors, which are unpredictable disruptions and disturbances, embarrassing circumstances, personal disrespect, and unpleasant encounters. It is a Likert-type questionnaire in which the individual responds to each item on a five-point scale ranging from "not at all" to "very much" depending upon the degree of anger.

\section{Statistical analysis}

Independent $t$-test and $\chi^{2}$-test were used to analyze the sociodemographic characteristics of both the depression group and the normal group. The severity of depression, anger, and aggression between the two groups was compared using an independent t-test. In addition, the correlation between the factors of each scale in the depression group was analyzed using Pearson correlation. Logistic regression analyses were conducted to examine the effects of anger and aggression factors on depression. All the data were statistically processed using SPSS (version 12.0) for Windows and $\mathrm{p}<0.05$ was applied as a statistical significance level.

\section{RESULTS}

\section{Demographic characteristics of the subjects}

Female subjects were included more in Depression group, while male subjects were included more in Normal elderly group. In Depression group, monthly income is significantly higher than Normal elderly group. However, other demographic characteristics such as age, education, marital status, habitation status were similar between the two groups (Table 1).

\section{Comparison of the severity of depression between depression group and normal elderly}

We compared the severity of depression between the depression group and the normal control group using the HDRS, BDI, and GDS. The average scores of the HDRS, BDI, and GDS were significantly higher in the patients with depressive disorders compared to the normal control group $(\mathrm{p}<0.05)$ (Table 2) .

Table 1. Demographic characteristics of the subjects

\begin{tabular}{|c|c|c|c|}
\hline Characteristic & Depression group $(\mathrm{N}=216)$ & Normal elderly $(\mathrm{N}=198)$ & p-value \\
\hline $\operatorname{Sex}(\%)^{*}$ & & & 0.00 \\
\hline Male & $46(21.3)$ & $70(35.4)$ & \\
\hline Female & $170(78.7)$ & $128(64.6)$ & \\
\hline $\operatorname{Age}(\mathrm{y}), \operatorname{Mean} \pm \mathrm{SD}^{\dagger}$ & $71.6 \pm 6.3$ & $72.6 \pm 5.9$ & 0.08 \\
\hline Education (y), Mean $\pm \mathrm{SD}^{\dagger}$ & $4.1 \pm 4.1$ & $4.3 \pm 4.4$ & 0.72 \\
\hline Monthly income, ${ }^{\dagger}$ Mean \pm SD & $60.4 \pm 91.9$ & $44.3 \pm 58.0$ & 0.04 \\
\hline Marital status (\%)* & & & 0.81 \\
\hline Married & $139(64.4)$ & $122(61.6)$ & \\
\hline Bereaved & $74(34.3)$ & $71(35.9)$ & \\
\hline Divorced/Separation & $2(0.9)$ & $3(1.5)$ & \\
\hline Unmarried & $1(0.5)$ & $1(0.5)$ & \\
\hline Others & $0(0.0)$ & $1(0.5)$ & \\
\hline Habitation status (\%)* & & & 0.85 \\
\hline Alone & $60(27.8)$ & $59(29.8)$ & \\
\hline Family without spouse & $18(8.3)$ & $15(7.6)$ & \\
\hline Spouse & $114(52.8)$ & $98(49.5)$ & \\
\hline Spouse and family & $24(11.1)$ & $26(13.1)$ & \\
\hline
\end{tabular}

Monthly income (10,000 Won). ${ }^{*}$ Chi-square test, ${ }^{\dagger}$ student's t-test. SD: standard deviation 
Table 2. Comparison of severity of depression between depression group and normal elderly group

\begin{tabular}{lccrr}
\hline Depression measures & Depression group $(\mathrm{N}=216)$ & Normal elderly $(\mathrm{N}=198)$ & $\mathrm{t}$ & $\mathrm{p}$-value \\
\hline HDRS (Mean $\pm \mathrm{SD})$ & $11.48 \pm 6.49$ & $5.45 \pm 5.46$ & 12.74 & $<0.001$ \\
BDI (Mean $\pm \mathrm{SD})$ & $10.95 \pm 9.11$ & $8.51 \pm 8.07$ & 13.87 & 0.004 \\
GDS $($ Mean \pm SD) & $13.70 \pm 8.02$ & $7.17 \pm 6.26$ & 13.94 & $<0.001$ \\
\hline
\end{tabular}

HDRS: Hamilton Depression Rating Scales, BDI: Beck Depression Inventory, GDS: Geriatric Depression Scale, SD: standard deviation

Table 3. Comparison of anger between depression group and normal elderly group

\begin{tabular}{|c|c|c|c|c|}
\hline & Depression group $(\mathrm{N}=216)$ & Normal elderly $(\mathrm{N}=198)$ & $\mathrm{t}$ & $\mathrm{p}$-value \\
\hline \multicolumn{5}{|l|}{ STAXI } \\
\hline Trait anger temperament* & $8.44 \pm 2.92$ & $9.26 \pm 3.37$ & 2.63 & 0.01 \\
\hline Trait anger reaction* & $6.97 \pm 2.77$ & $8.97 \pm 3.37$ & 6.56 & $<0.00$ \\
\hline State anger & $10.46 \pm 2.17$ & $10.21 \pm 1.22$ & -1.47 & 0.14 \\
\hline Anger-in* & $10.96 \pm 4.25$ & $12.41 \pm 4.41$ & 3.41 & 0.00 \\
\hline Anger-Out* & $10.11 \pm 2.75$ & $11.94 \pm 3.59$ & 5.78 & $<0.00$ \\
\hline Anger-control* & $15.60 \pm 4.73$ & $18.83 \pm 4.56$ & 7.05 & $<0.00$ \\
\hline \multicolumn{5}{|l|}{ AQ } \\
\hline Physical aggression & $15.17 \pm 4.82$ & $15.29 \pm 4.73$ & 0.26 & 0.80 \\
\hline Verbal aggression* & $9.91 \pm 3.90$ & $11.42 \pm 4.05$ & 3.87 & $<0.00$ \\
\hline Anger & $14.22 \pm 3.52$ & $14.61 \pm 4.42$ & 0.98 & 0.33 \\
\hline Hostility* & $12.87 \pm 4.98$ & $14.03 \pm 4.41$ & 2.49 & 0.01 \\
\hline \multicolumn{5}{|l|}{ RI } \\
\hline Disturbances* & $18.87 \pm 7.07$ & $26.06 \pm 9.19$ & 2.35 & $<0.00$ \\
\hline Embarrassing* & $8.90 \pm 3.62$ & $11.31 \pm 4.42$ & 0.00 & $<0.00$ \\
\hline Disrespect* & $13.35 \pm 4.73$ & $16.70 \pm 5.38$ & 0.00 & $<0.00$ \\
\hline Unpleasant & $4.33 \pm 2.03$ & $4.54 \pm 2.20$ & 0.319 & 0.32 \\
\hline
\end{tabular}

${ }^{*} \mathrm{p}<0.05$. STAXI: state and trait anger inventory, AQ: aggression questionnaire, RI: reaction inventory

\section{Comparison of anger factors between depression group and normal elderly}

Elderly patients with depression showed significantly lower scores in the trait anger temperaments, trait anger reactions, trait anger, anger in, anger out, anger control, and anger expression on the STAXI than Normal elderly $(\mathrm{p}<0.05)$. The score of verbal aggression and hostility on AQ were lower and the scores of unpredictable disruption and disturbances, embarrassing situations, and personal disrespect on the RI were significantly lower in Depressive group compared to Normal elderly $(\mathrm{p}<0.05)$ (Table 3$)$.

\section{Correlations between depressive symptoms and anger in depression group}

Three depression symptoms scales (HDRS, BDI, and GDS) and multiple factors of STAXI, such as trait anger temperaments, trait anger reactions, state anger, anger in, and anger out showed significant positive correlations $(\mathrm{p}<0.05)$. In addition, the scores of HDRS, BDI, and GDS had considerable positive correlations with physical aggression, anger, and hostility scores on the AQ Finally, the more severe the depressive symptoms were present, the more severe the anger reaction to unpredictable disruption and disturbances, embarrassing situations, and personal disrespected factors scores on the RI were $(\mathrm{p}<0.05)$. Conversely, significant negative correlations were observed for the HDRS, BDI, and GDS scores and the anger control scores $(\mathrm{p}<0.05)$ (Table 4$)$.

\section{Effects of anger factors on depression}

To examine the effects of anger factors on depression, odds ratios were obtained using logistic regression analyses. The odd ratios were calculated as the ratios of the incremental risks of depression per 1-point increases in the anger-related factors (Table 5).

Among factors of STAXI, the score of state anger was the most affected by the risk of depression \{odds ratio $(\mathrm{OR})=$ 1.24 , confidence interval $(\mathrm{CI})=1.03-1.51\}$. The scores of angerin, anger-out, and anger control increased by 1 point, whereas the risk of depression decreased by 0.80 times, 0.90 times, and 0.83 times $(\mathrm{OR}=0.80, \mathrm{CI}=0.73-0.88$; $\mathrm{OR}=0.90, \mathrm{CI}=0.82$ $0.98 ; \mathrm{OR}=0.83, \mathrm{CI}=0.78-0.89)$, respectively.

Regarding AQ, the verbal aggression score increased by 1 


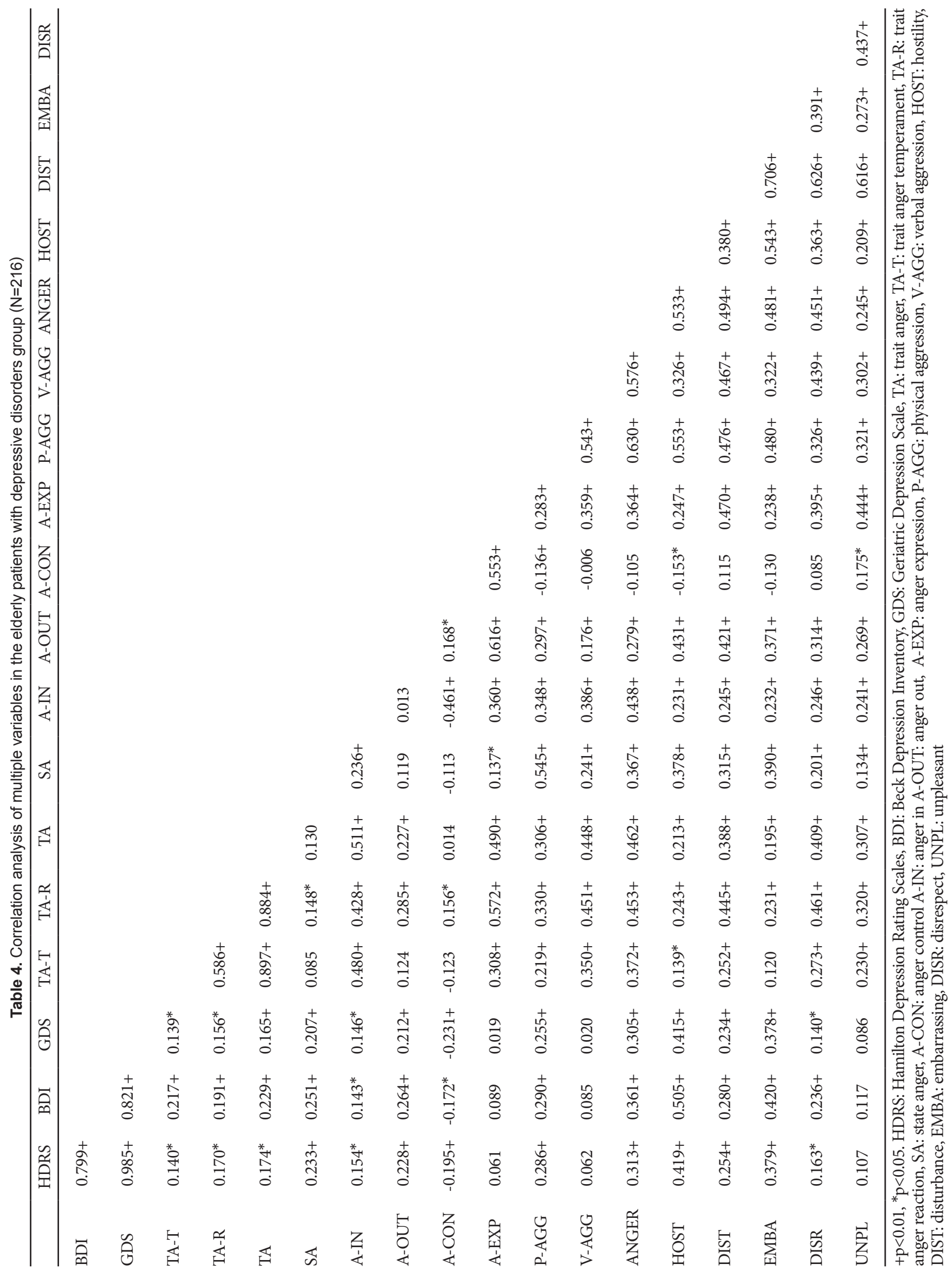


Table 5. Linear logistic regression analysis of anger factors between depression group and normal elderly group

\begin{tabular}{|c|c|c|c|c|}
\hline & B & S.E. & Odds ratio & $95 \% \mathrm{CI}$ \\
\hline \multicolumn{5}{|l|}{ STAXI } \\
\hline Trait anger temperament & 0.04 & 0.06 & 1.04 & $0.92-1.18$ \\
\hline Trait anger reaction & -0.03 & -0.06 & 0.98 & $0.86-1.10$ \\
\hline State anger* & 0.22 & 0.10 & 1.24 & $1.03-1.51$ \\
\hline Anger-in* & -0.22 & 0.05 & 0.80 & $0.73-0.88$ \\
\hline Anger-out* & -0.11 & 0.05 & 0.90 & $0.82-0.98$ \\
\hline Anger-control* & -0.19 & 0.03 & 0.83 & $0.78-0.89$ \\
\hline \multicolumn{5}{|l|}{ AQ } \\
\hline Physical aggression & 0.07 & 0.04 & 1.08 & $1.00-1.16$ \\
\hline Verbal aggression* & -0.09 & 0.05 & 0.91 & $0.84-1.00$ \\
\hline Anger* & 0.20 & 0.05 & 1.22 & $1.11-1.35$ \\
\hline Hostility & -0.02 & 0.04 & 0.98 & $0.91-1.06$ \\
\hline \multicolumn{5}{|l|}{ RI } \\
\hline Disturbances* & -0.21 & 0.04 & 0.81 & $0.76-0.88$ \\
\hline Embarrassing & 0.02 & 0.05 & 0.98 & $0.88-1.10$ \\
\hline Disrespect & 0.05 & 0.04 & 1.01 & $0.94-1.10$ \\
\hline Unpleasant* & 0.51 & 0.09 & 1.67 & $1.40-1.99$ \\
\hline
\end{tabular}

$\chi^{2}=207.7, \mathrm{df}=14,{ }^{*} \mathrm{p}<0.05$. STAXI: State and Trait Anger Inventory; AQ: aggression questionnaire; RI: reaction inventory, B: regression coefficent, S.E: standard error, CI: confidence interval

point, the risk of depression decreased by 0.91 times $(\mathrm{OR}=$ $0.91, \mathrm{CI}=1.03-1.51$ ), while the anger score increased by 1 point, the risk of depression increased by 1.22 times $(\mathrm{OR}=1.22, \mathrm{CI}=$ 1.11-1.35).

The score of unpredictable disruptions and disturbances factors of RI increased by 1 point, the risk of depression decreased by 0.81 times $(\mathrm{OR}=0.81, \mathrm{CI}=0.76-0.88$ ), while the risk of depression increased by 1.67 times $(\mathrm{OR}=1.67, \mathrm{CI}=1.40-1.99)$ in the case of anger reactions to unpleasant encounters factors.

\section{DISCUSSION}

This study was conducted to examine levels of anger in elderly depressed patients, correlations of anger with depression symptoms, and effects of diverse anger factors on depression.

The STAXI are included in anger experience and anger expression style. In addition, anger experience can be obtained from trait anger and state anger. In the three facets of anger expression, people generally suppress the anger (anger in), express the anger toward other persons or objects in their environments (anger out), or try to control angry feelings (anger control). ${ }^{1}$ In our results, elderly patients with depressive disorders have lower trait anger and anger expression compared to normal elderly. Moreover, elderly depressed patients showed lower hostility and verbal aggression than normal elderly. They tend to be less triggered into anger by unpredictable disruptions and disturbance situation, embarrassing circumstances, and personal disrespect situation than non-depressed elderly. However, these results are different from those of Riley et al. ${ }^{34}$ that depressed adult patients reported stronger subjective anger experiences and suppressed anger expression than normal persons did. In that study, the subjects were adult aged and had a posttraumatic stress disorder as a comorbidity. In addition, reports about comparison anger between depressive patients and normal in elderly are rare. Whether our results represent elderly persons' characteristics or methodological limitations of subjective questionnaires should be verified through future studies.

The severity of depressive symptoms experienced by the elderly were positively correlated with most of the anger factors, except anger control of STAXI, verbal aggression of AQ, and unpleasant situation of RI. Interestingly, the level of depression only showed significant negative correlations with the anger control on the STAXI. Therefore, even though elderly patients suffering from more severe depression may experience stronger anger, they may suppress anger further or may express with low levels of control as the anger expression style. These results are consistent with a study by Fava et al..$^{35}$ that 30 $40 \%$ of patients with depressive disorders showed anger attacks and that those who experienced anger attacks might be afraid of feeling out of control and might be more afraid of their possible aggression. Patients with depressive disorders seemed to be vulnerable to disturbed situations, embarrassing situations, and disrespected situations among the anger stim- 
ulating situations.

The logistic regression analyses for odds ratio were conducted based on whether anger factors could affect elderly depression as one of the risk factors. If state anger on the STAXI and anger on the AQ are higher, the possibility of depression will be higher; and if anger control, anger in, and anger out on the STAXI and verbal aggression on the AQ are higher, then the possibility of non-depression states will be higher. The people who lack of ability to express anger such as controlling, suppressing, or expressing anger seem to be vulnerable to depression. However, since the odd ratios between different variables of anger scales are not relatively as high as $0.80-1.67$, it may not be possible to conclude that anger work as important causes of the occurrence of depression.

Finally, clinical implications related to our results are reviewed as follows. In clinical practice, depressive patients frequently state problems related to anger as one of their emotion or in interpersonal relations. Elderly individuals, especially Koreans, often notice that they are experiencing Hwabyung. Hwabyung (anger syndrome) is also classified as a culture bound syndrome in the DSM-IV, and can be a psychogenic or reactive chronic anger disorder developed due to the suppression of anger. ${ }^{20}$ In most psychotherapy fields, anger expression is actively recommended as a therapeutic intervention against anger. However, uncontrolled anger expression may cause harm to close relationships and eventually lead to self-destruction. Although anger expression may reduce depression, the outcomes are not consistent. ${ }^{36}$ Our results have indicated that the ability to express anger such as controlling, suppressing, or expressing anger is reduced in elderly depressive patients and that the more severe the depressive symptoms, the more difficult the anger was to control in depressive patients. Therefore, the present important implications can be applied to treatment plans of depressive patients, that is, controlling anger leads to reduced depressive symptoms. In addition, cognitive approach of knowing the target of one's hostility and interpreting events that trigger anger will differently be helpful. ${ }^{6}$ Also, treatment strategies such as requesting modification of human relations may be meaningful.

This study has several limitations. First, the number of subjects was not enough to make comparisons between the patients with depressive disorders and those that were the normal control. Second, there were differences in sex distributions and economic levels between patients group and normal elderly, thus, these demographic factors might have affected the results. Third, even though the subjects were diagnosed with observer assessment scales such as structural interviews through the MINI and the HDRS, the anger assessments relied on selfreport scales. There is lack of differentiating among various aspects of anger, such as cognition, behavior or emotion. In our study, defense mechanisms such as denial or confounding factors that disturb accurate assessments of emotions might have affected the results. Fourth, the patients with depressive disorders who participated in the study had already been receiving treatment. Although the scores of anger in the patients with depressive disorders group were significantly higher than those of normal controls, treatment for depression might have affected their perceptions of anger.

In spite of these limitations, this study may have a significant implication that it is the first report that focused on anger in elderly patients with depressive disorders. In addition, this study will provide opportunities to broaden the understanding of elderly patients with depressive disorders accompanied by anger.

\section{REFERENCES}

1. Spielberger CD, Johnson EH, Russell SF, Crane RJ, Jacobs GA, Worden TJ. The Experience and Expression of Anger: Construction and Validation of an Anger Expression Scale. In: Chesney MA, Rosenman RH, Editors. Anger and Hostility in Cardiovascular and Behavioral Disorders. Washington, DC: Hemisphere Publishing. 1985, p.5-30.

2. Biaggio MK, Supplee K, Curtis N. Reliability and validity of four anger scales. J Pers Assess 1981;45:639-648.

3. Ramírez JM, Andreu JM. Aggression, and some related psychological constructs (anger, hostility, and impulsivity); some comments from a research project. Neurosci Biobehav Rev 2006;30:276-291.

4. Barefoot JC, Beckham JC, Haney TL, Siegler IC, Lipkus IM. Age differences in hostility among middle-aged and older adults. Psychol Aging 1993;8:3-9.

5. Barefoot JC, Peterson BL, Dahlstrom WG, Siegler IC, Anderson NB, Williams RB Jr. Hostility patterns and health implications: correlates of Cook-Medley Hostility Scale scores in a national survey. Health Psychol 1991;10:18-24.

6. Schless AP, Mendels J, Kipperman A, Cochrane C. Depression and hostility. J Nerv Ment Dis 1974;159:91-100.

7. Weissman MM, Klerman GL, Paykel ES. Clinical evaluation of hostility in depression. Am J Psychiatry 1971;128:261-266.

8. Bland R, Orn H. Family violence and psychiatric disorder. Can J Psychiatry 1986;31:129-137.

9. Eronen M, Hakola P, Tiihonen J. Mental disorders and homicidal behavior in Finland. Arch Gen Psychiatry 1996;53:497-501.

10. Swanson JW, Holzer CE 3rd, Ganju VK, Jono RT. Violence and psychiatric disorder in the community: evidence from the Epidemiologic Catchment Area surveys. Hosp Community Psychiatry 1990;41:761770 .

11. Tedlow J, Leslie V, Keefe BR, Alpert J, Nierenberg AA, Rosenbaum JF, et al. Axis I and Axis II disorder comorbidity in unipolar depression with anger attacks. J Affect Disord 1999;52:217-223.

12. Gould RA, Ball S, Kaspi SP, Otto MW, Pollack MH, Shekhar A, et al. Prevalence and correlates of anger attacks: a two site study. J Affect Disord 1996;39:31-38.

13. Brodaty H, Low LF. Aggression in the elderly. J Clin Psychiatry 2003; 64(Suppl 4):36-43.

14. Lyketsos CG, Steele C, Galik E, Rosenblatt A, Steinberg M, Warren A, et al. Physical aggression in dementia patients and its relationship to depression. Am J Psychiatry 1999;156:66-71.

15. Raskind MA. Evaluation and management of aggressive behavior in the elderly demented patient. J Clin Psychiatry 1999;60(Suppl 15):45-49.

16. Kellner R, Hernandez J, Pathak D. Self-rated inhibited anger, somatization and depression. Psychother Psychosom 1992;57:102-107. 
17. Koh KB, Kim DK, Kim SY, Park JK. The relation between anger expression, depression, and somatic symptoms in depressive disorders and somatoform disorders. J Clin Psychiatry 2005;66:485-491.

18. Hodapp V, Sicker G, Wick AD, Winkelsträter R. Anger and risk of suicide. Study of elderly psychiatric patients. Nervenarzt 1997;68:55-61.

19. Lin KM. Hwa-Byung: a Korean culture-bound syndrome? Am J Psychiatry 1983;140:105-107.

20. Min SK. A study of the concept of hwabyung. J Korean Neuropsychiatr Assoc 1989;28:604-616.

21. Sheehan DV, Lecrubier Y, Sheehan KH, Amorim P, Janavs J, Weiller E, et al. The Mini-International Neuropsychiatric Interview (M.I.N.I.): the development and validation of a structured diagnostic psychiatric interview for DSM-IV and ICD-10. J Clin Psychiatry 1998;59(Suppl 20):22-33.

22. Hamilton M. A rating scale for depression. J Neurol Neurosurg Psychiatry 1960;23:56-62.

23. Yi JS, Bae SO, Ahn YM, Park DB, Noh KS, Shin HK, et al. Validity and reliability of the Korean version of the Hamilton Depression Rating Scale (K-HDRS). J Korean Neuropsychiatr Assoc 2005;44:456-465.

24. Beck AT, Ward CH, Mendelson M, Mock J, Erbaugh J. An inventory for measuring depression. Arch Gen Psychiatry 1961;4:561-571.

25. Han HM, Yeom TH, Shin YW, Kim KH, Yoon DJ, Jung KJ. A Standardiz-ation study of beck depression inventory in Korea. J Korean Neuropsychiatr Assoc 1986;25:487-502.

26. Yesavage JA, Brink TL, Rose TL, Lum O, Huang V, Adey M, et al. Development and validation of a geriatric depression screening scale: a prelim- inary report. J Psychiatr Res 1982-1983;17:37-49.

27. Cho MJ, Bae JN, Suh GH, Hahm BJ, Kim JK, Lee DW, et al. Validation of Geriatric Depression Scale, Korean version (GDS) in the assessment of DSM-III-R major depression. J Korean Neuropsychiatr Assoc 1999; 38:48-63.

28. Spielberger CD. State-Trait Anger Expression Inventory: Professional Manual. Odessa, Florida: Psychological Assessment Resources; 1988.

29. Chon KK, Kim DY, Yi JS. Development of the STAXI-K: IV. Korean J Art Ther 2000;7:33-50.

30. Buss AH, Perry M. The aggression questionnaire. J Pers Soc Psychol 1992;63:452-459.

31. Seo SK, Kwon SM. Validation study of the Korean version of the aggression questionnaire. Korean J Clin Psychol 2002;21:487-501.

32. Cho YW, Kim JL, Kim SY, Wang SK, Chee IS. A standardization of the Korean version of the reaction inventory. J Korean Soc Biol Ther Psychiatry 2009;15:130-139.

33. Evans DR, Stangeland M. Development of the reaction inventory to measure anger. Psychol Rep 1971;29:412-414.

34. Riley WT, Treiber FA, Woods MG. Anger and hostility in depression. J Nerv Ment Dis 1989;177:668-674.

35. Fava M, Rosenbaum JF. Anger attacks in patients with depression. J Clin Psychiatry 1999;60(Suppl 15):21-24.

36. Wadsworth AP Jr, Barker HR Jr. A comparison of two treatments for depression: the antidepressive program vs. traditional therapy. J Clin Psychol 1976;32:445-449. 